\title{
Author Correction: Empirical evaluation of the stringency and design of renewable portfolio standards
}

\author{
Sanya Carley (D), Lincoln L. Davies, David B. Spence and Nikolaos Zirogiannis (D)
}

Correction to: Nature Energy https://doi.org/10.1038/s41560-018-0202-4, published online 23 July 2018.

In the version of this Article originally published, there was a data entry error in Table 1 for a single variable, eligibility of non-renewable resources in a renewable portfolio standard. This affected the descriptive statistics in Table 1 and Fig. 4 and the regression results and efficiency variable in Table 2. It also affects parts of the text, Table 3 and the Supplementary Information.

In the introduction, the sentence that reads "We also find that solar generation can be crowded out when an RPS policy credits other non-renewable sources" has now been changed to "We also find that renewable energy capacity can be crowded out when an RPS policy credits energy efficiency."

In the section titled "A brief history of RPS policies in the United States," the following line has been deleted: "By contrast, crediting non-renewables was a rarer event until 2011, when several states modified their laws in this regard."
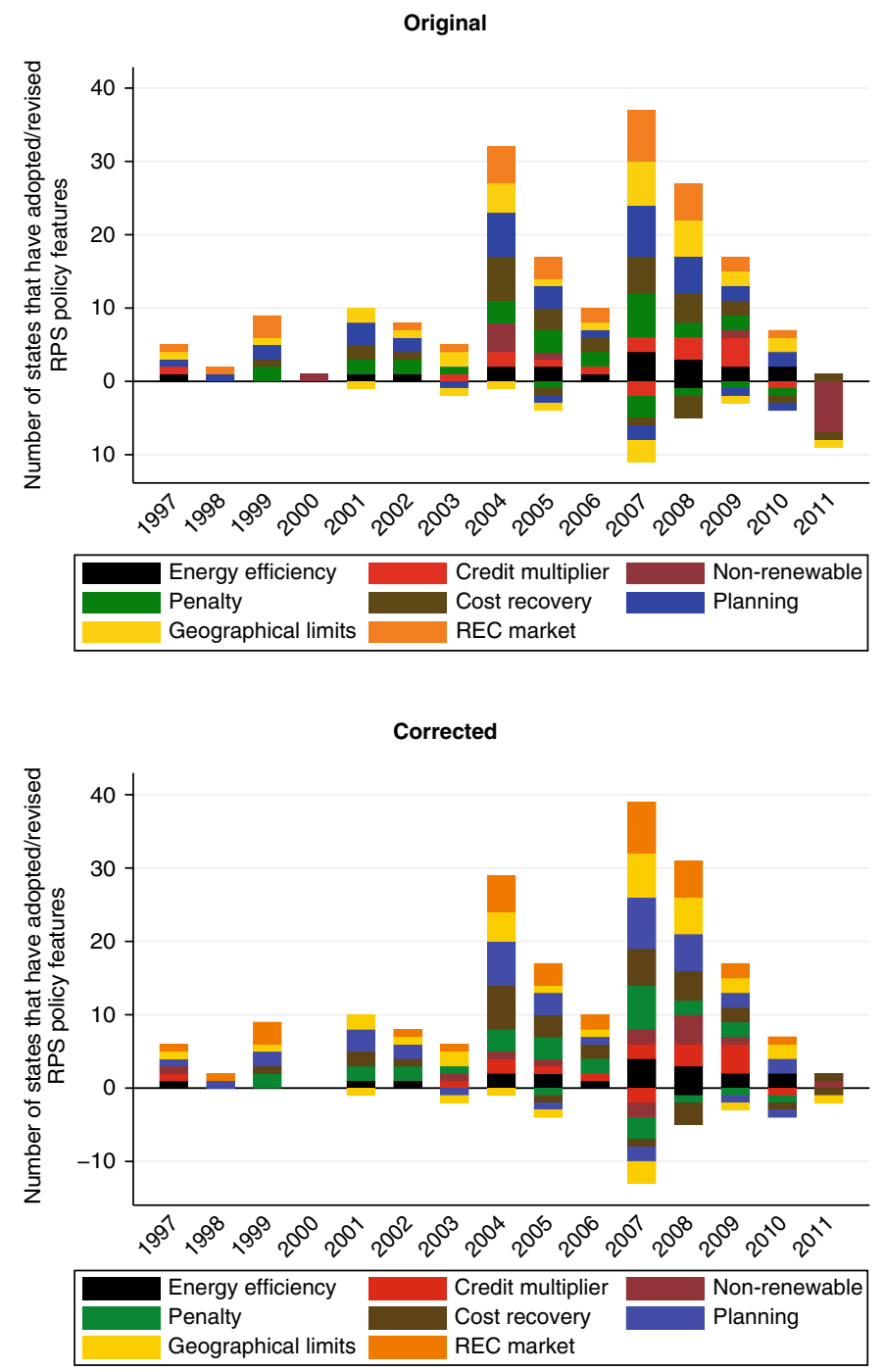

Fig. 4 | Original and Corrected. 
In Table 1, the descriptive statistics for the non-renewable energy variable were mistakenly given as 0.033 (mean) and 0.17 (standard deviation); these values have now been corrected to 0.069 and 0.25 respectively.

Figure 4 has been updated to reflect new values for non-renewable policy features.

The corrected variable resulted in extensive changes to Table 2 and Table 3.

In the "Regression analysis" section, the sentence that read "The other design feature that is statistically significant in the main models is whether a state's RPS policy allows non-renewable energy sources to count toward compliance" has been changed to "The other design feature that is statistically significant in the main models is whether a state's RPS policy allows energy efficiency to count toward compliance." The sentence that read "Design features seem particularly important for solar generation, and collectively account for over $17 \%$ of the total variation in the solar generation variable" has been changed to "Design features seem particularly important for solar generation, and collectively account for over $15 \%$ of the total variation in the solar generation variable".

In the "Regression analysis" section, the sentence that read "Wind generation is also associated with both liberal government ideology and conservative citizen ideology, which may be because rural regions tend, on average, both to have higher wind capacity and to be more conservative" has be changed to "Wind generation is also associated with more liberal government ideology."

In the "Conclusions" section, the sentence that read "Allowing energy sources that are not renewable to count toward a mandate, for example, is associated with much lower rates of solar generation and overall renewable energy capacity" has been changed to "Allowing energy efficiency to count toward a mandate, for example, is associated with lower rates of renewable energy capacity."

In the Supplementary Information, the following sentence was deleted from page 2: "The contemporaneous effect of the treatment variable (RPSt) has a significant but very small coefficient when two and three leads are included and only in the renewable share model (Model 1, presented in Supplementary Table 2)." In the following sentence, the text "This result suggests" has been changed to "These results suggest". On page 3, the text "save the flip in sign and statistical significance-at the ten percent significance threshold-on the stringency variable in the model predicting wind generation" was appended to the end of the last sentence. Supplementary Tables $1-8$ and 10 have been updated with revised regression results.

These corrections have now been made.

Published online: 6 February 2019

https://doi.org/10.1038/s41560-019-0334-1 